\title{
Robotic-Assisted Laparoscopic Redo Nissen Fundoplication. Does it Offer Advantages in Children?
}

\author{
Mario Navarrete Arellano* \\ Hospital Central Militar, Mexico
}

Submission: June 27, 2019; Published: August 28, 2019

*Corresponding author: Mario Navarrete Arellano, Consultorio 1C, Módulo B, Torre Sur, Calle Sur 136 No. 116, Las Américas, Álvaro Obregón, C.P. 01120. Mexico City, Mexico.

Abstract

Objective: The experience in RALRNF and its advantages in children is presented.

Materials and Methods: A prospective, observational, and longitudinal study from March 2015 to March 2019, in children treated with RALRNF. Parameters examined: demographic data, diagnoses, surgical technique, recurrence of our PRF, previous surgical approach, time of console surgery, TO surgical findings, bleeding, hemotransfusions, complications, conversions, PO stay, and follow-up. Surgical system used was "da Vinci model, Si versión" (Intuitive Surgical, Inc., Sunnyvale, CA. U.S.A). Measures of central tendency were used. Research Ethics Committee of Hospital approved the study.

Results: In 4 years, 19 RALRNF cases were performed in children; 66.16\% were male; averages in age was 10.3 years, stature $135.2 \mathrm{~cm}$ and weight was $36.3 \mathrm{~kg}$. Previous fundoplications was 10 open, 6 laparoscopic and 3 robotic. Recurrence rate of our PRF cases was $6 \%$. TO findings: $\mathrm{HH}$ and wrap dehiscence $52.63 \%$ and only wrap dehiscence $47.37 \%$. Average time of console surgery was 280 min. Conversion rate and hemotransfusion was $5.2 \%$. TO complications occurred in $21 \%$ and not alter PO evolution, PO complications and mortality 0\%. A RALRNF failure occurred (5.2\%). Averages PO stay was 2.2 days, and follow-up 24.1 months.

Conclusion: The failed fundoplication is frequent, and RF is complex, difficult and laborious technique. With the RALRNF we achieved low risk of conversion, no complications, few hemotransfusion, short TO stay and low recurrence rate for our patients. The RALRNF if offers advantages to the children. Only expert pediatric surgeons solve them, by conventional laparoscopy. There are few publications of RALRNF in children.

Keywords: Robotic assisted; Robotic surgery; Laparoscopic surgery; Pediatric surgery; Robotic gastrointestinal surgery; Redo fundoplication; Redo minimally invasive surgery; Children

Abbreviations: RALRNF: Robotic-Assisted Laparoscopic Redo Nissen Fundoplication; PRF: Primary Robotic Fundoplication; TO: Transoperative; PO: postoperative; HH: Hiatal Hernia; LPNF: Laparoscopic Primary Nissen Fundoplication; RF: Redo Fundoplication; GERD: Gastroesophageal Reflux Disease; LRNF: Laparoscopic Redo Nissen fundoplication; RRNF: Robotic Redo Nissen Fundoplication; GI: Gastrointestinal

\section{Introduction}

Gastroesophageal reflux is very common in children and can often leads to reflux-esophagitis, peptic esophageal strictures, Barrett's esophagus. If the conservative treatment fails a patient needs surgical treatment as well as those who suffer from complications and $\mathrm{HH}[1,2]$. Fundoplication is considered a mainstay in the surgical treatment of gastro-esophageal reflux [3]. The most popular operation is laparoscopic primary Nissen fundoplication (LPNF) with the efficiency of more than $80 \%$, and there are authors who refer to this procedure as the gold standard $[1,4]$.
Pediatric endoscopic surgery in children dates from 1971, the first case of laparoscopy in pediatric surgery was reported by Stephen Gans in this year, in his landmark publication, "Advances in Endoscopy of Infants and Children," as a peritoneoscopy. The term peritoneoscopy was soon replaced by Pediatric Laparoscopy $[5,6]$. But the first publications of laparoscopic fundoplication in children date from the early nineties [7-9].

On the other hand, the first minimally invasive robot-assisted surgery in children was the fundoplication technique, were carried out by Meininger et al. [10] in July 2000 and reported in 
April $2001[10,11]$. The fundoplication is a leading application of robotic surgery in children in GI area, since then [12,13].

In children, the current alternatives for fundoplication are the approaches: open, laparoscopic and robotic for fundoplication, and the main challenge is to redo fundoplications (RF) in patients who fail the primary procedure, this occurs in a wide range between $2.6 \%$ to $42 \%$. [1,3,14-16]. On the other hand, the recurrence of gastroesophageal reflux disease (GERD) after surgical treatment can be presented independently of the surgical approach used, as evidenced by Ru W et al., [17] in a systematic review and a meta-analysis of patients undergoing laparoscopic or open primary Nissen fundoplication, they did not find a significant difference in the recurrence [17]. Other study by Thomas JF, et al, they compare recurrence of GERD in children through a study randomized, laparoscopic (44 patients) VS open primary Nissen fundoplication (43 patients), with the main outcome measure was recurrence of GERD. The results where, significantly more patients that undergoing LPNF (37\%) experienced recurrence of GERD, compared with only $7 \%$ to those undergoing open primary Nissen fundoplication [18], also with the robotic approach, failures of primary fundoplication occur between $2 \%$ to $4.7 \%$ [19-21]. So, we can say that the recurrence of GERD after surgical treatment is frequent.

The most used approachesto perform the Nissen fundoplication in the world are the open and the laparoscopic. The robot-assisted has only been slowly adopted for use in children and in particular with the technique of the primary Nissen fundoplication, there is special controversy between laparoscopy and robotic approach, because pediatric surgeons experts in laparoscopy and several published studies, comparing both approaches, no significant advantages are observed with the use of the robotic approach, but yes, a big drawback, that robotic surgery increases costs $[3,22,23]$. However, robotic surgery offers advantages for the patient and for the surgeon, which means that procedures for the patient are safer.

It's important to mention in relation to the experience in the world of conventional laparo-thoracoscopic surgery in children, that the application of this, have at least a decade more experience that the robotic surgery and a significant number of publications compare conventional laparoscopic results with robotic surgery, and where in the latter they include the learning curve of surgeons, what can influence the results and skew the conclusions, as to time of console surgery, complications, and conversions [22,24].

For example, Rothenberg with his vast experience in minimally invasive surgery in children, in his report on LPNF for a 20-years period and procedures realized were 2008, your results are: average operative time dropped from 109 minutes for the first 30 cases to 35 minutes for the last 30 cases. In redo surgery, of the 283 procedures that were RF, the complications rates were intraoperative $2.2 \%$ and PO $4.2 \%$, The overall wrap failure rate for primary fundoplications was $4.6 \%$ and was highest in the $<6$-month age group. Based on the results presented, the author states that LPNF should be considered the gold standard for antireflux procedures. But, even with the author's experience, the failure rate in the group of the laparoscopic redo Nissen fundoplication (LRNF), was 6.8\% [4].

If conventional laparoscopy is used, the reconstructive and complex procedures are very challenging, and long periods of time are necessary to acquire the appropriate skills and confidence, vs. robotic surgery, the learning curve is shorter [25-28].

There are hospital centers in the world that reoperate the GERD, through open redo Nissen fundoplication, even having with minimal invasion, and in other studies they do not mention the option of laparoscopy [29-32] of what is inferred, the complexity of the surgical technique and probably the lack of experience in minimally invasive surgery.

Open redo Nissen Fundoplication or LRNF has a variable failure rate $6 \%$ to $42 \%$, [4,16,33-35], what translates the high complexity of this pathology.

The robotic surgery enables more refined hand-eye coordination, superior suturing skills, better dexterity, and precise dissection. It is achieved by the characteristics of robotic surgical platforms that include motion scaling, greater optical magnification, 3D and stereoscopic vision, increased articulated instrument tip dexterity, tremor filtration, operator-controlled camera movement, and elimination of the fulcrum effect [3639], and all of this translates into greater safety for patients and advantages for the surgeon.

Robotic surgery is one technology that has gained an enormous surge in use on adults. The general surgical applications have been quite varied in adults [40-43].

There have been few reports that have been published for robotic general pediatric surgery [44-53]. Numerous case reports, case series, and comparative studies have unequivocally demonstrated that robotic surgery in children is safe [54].

Cundy TP et al, [20] using cumulative summation analysis to define the learning curve for PRF, time-based surgical process outcomes were evaluated, as well as clinical outcomes, the authors identified numerous well-defined learning curve trends to affirm that experience confers significant temporal improvements, for the time of console surgery from procedure 34 .

$\mathrm{RF}$ is generally more difficult because anatomic planes are obscured by adhesions from the previous surgery, whether it is open or laparoscopic and the very features that distinguish minimally invasive surgery can be the cause of concern in laparoscopic redo surgery because of adhesions. Thus, the application of laparoscopy to redo surgery, particularly in children, is controversial because of safety [33]. So complex laparoscopic surgery should be performed only by an expert pediatric surgeon, and with a high volume of surgical procedures.

Children presenting for initial or RF after feeding gastrostomy are a subset of patients that may benefit from the robotic approach. 
This technique is particularly difficult in standard laparoscopy without dislodgement of the gastrostomy, particularly if there are abundant adhesions or a replaced left hepatic artery to preserve [55].

There is a scarcity of publications from Latin American countries to date that describe pediatric patients who have undergone robotic surgery $[13,56,57]$, and in relation to the number of RALRNF publications in the world, it is also limited, including the adult and pediatric population [20,58-62]. Objective of this study is to present our experience in RALRNF and highlight its advantages in children.

\section{Material and Methods}

This prospective, observational and longitudinal study of the robotic redo Nissen fundoplication (RRNF) performed on a pediatric population was conducted from March 24, 2015 to March 27, 2019. Our hospital is a public tertiary care facility, and the robotic surgery program include specialty of the pediatric surgery.

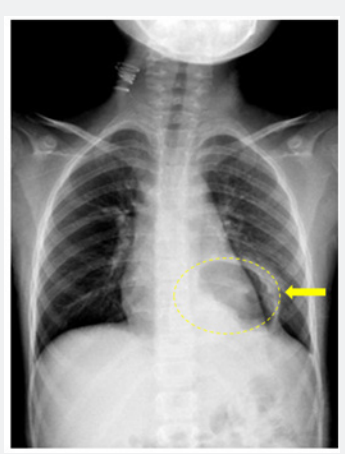

Figure 1: Male patient, 17 years old, 102kg, antecedent of LPNF, simple Rx with supradiaphragmatic radiolucency image by $\mathrm{HH}$ and recurrence of severe symptoms of gastroesophageal reflux (arrow and yellow circle).

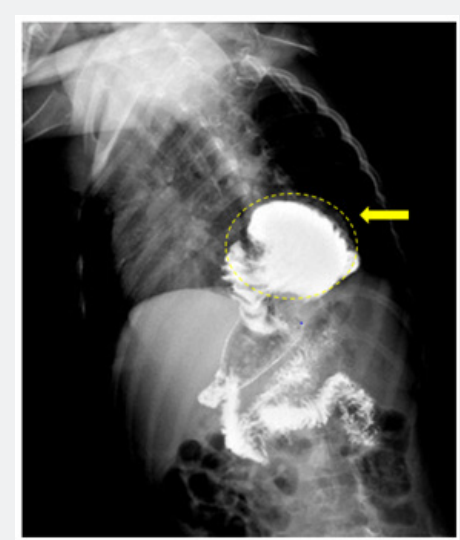

Figure 2: Patient figure 1, Rx barium study, shows important herniation of the stomach to the thorax, complex HH (arrow and yellow circle).

The diagnosis of recurrence of reflux and its complications was suspected by the presence of one or more of the following symptoms and signs: vomiting, regurgitation, heartburn, epigastric pain, dysphagia, coughing and wheezing, pneumonia, life-threatening events (apneic spells), among others, and confirmed with upper GI tract X-Ray (Figure 1 \& 2), endoscopy, and in some cases impedance-pH measurement.

Non-random simples were, all pediatric patients who required RF included.

The parameters recorded were gender, age, weight, height, diagnoses, surgical technique, elapsed time of console surgery, estimated bleeding, hemotransfusion, complications, conversions,
PO hospital stay, and follow-up. The Clavien-Dindo classification of surgical complications was used $[63,64]$.

The surgical system used was the da Vinci model, Si version (Intuitive Surgical, Inc., Sunnyvale, CA. U.S.A). We used $8 \mathrm{~mm}$ robotic instruments and trocars, 3 robotic work arms, $8.5 \mathrm{~mm}$ or $12 \mathrm{~mm}$ robotic $30^{\circ}$ lens for a three-dimensional camera, and a $5 \mathrm{~mm}$ trocar laparoscopic for one assistant.

The docking charts for robotic surgery that are suggested for surgical techniques in adults were not applicable in infant patient, in this case, $4-5 \mathrm{~cm}$ of separation was possible between each trocar, due to the limited space in such a small patient. The surgical tecnique used was Nissen Floppy fundoplication (RALRNF) (Figures 3-8). 


\section{Academic Journal of Pediatrics \& Neonatology}

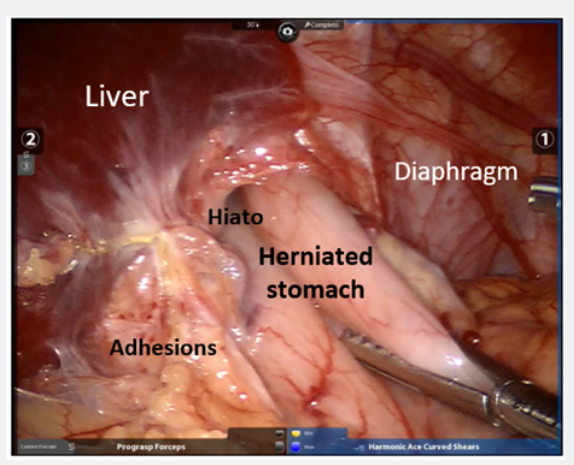

Figure 3: Patient figure 1, initial TO image, large hiatus, stomach herniated to the thorax, and dense adhesions, the RALRNF starts

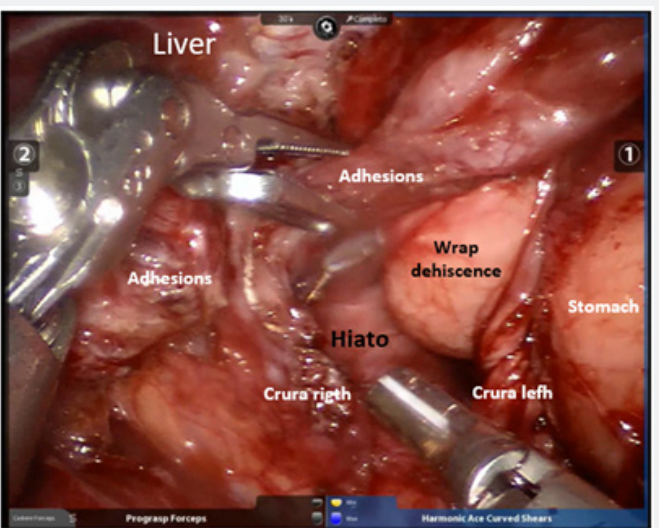

Figure 4: TO image, herniated stomach was reduced, adherensiolysis was partially performed, both pillars of the crura were identified, the hiatus is large, and the wrap is dehiscent.

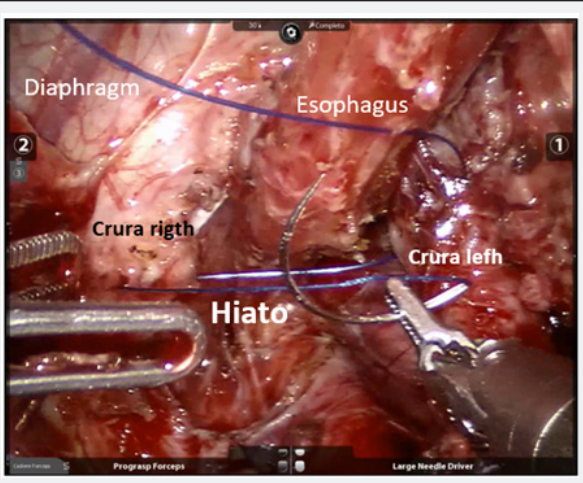

Figure 5: TO image, adherenciolisis was finished, the anatomy was completely identified, and hiatoplasty was initiated.

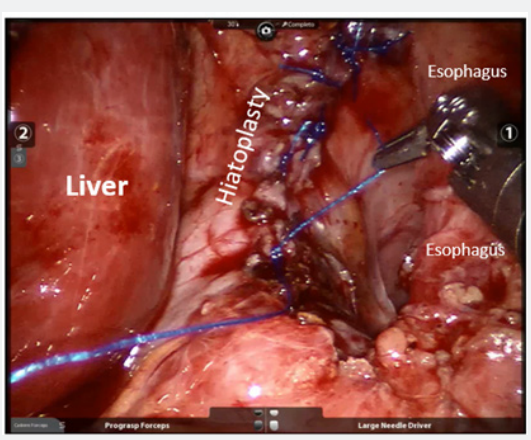

Figure 6: TO image, the hiatoplasty with nonabsorbable suture is concluded. 


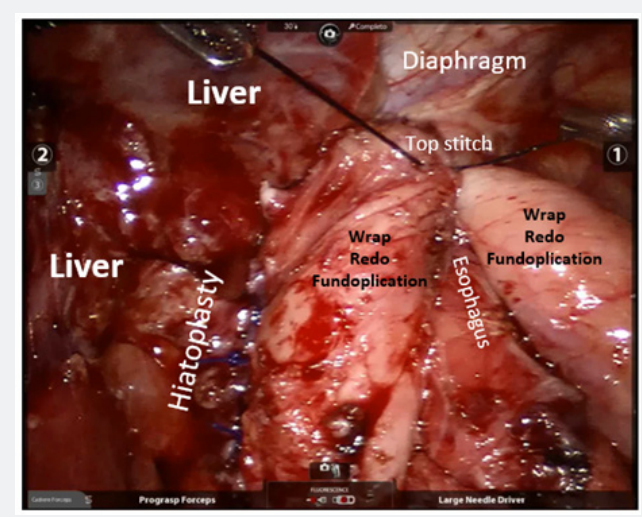

Figure 7: TO image, the RF starts, taking care of the technical details, the top stitch has been applied.

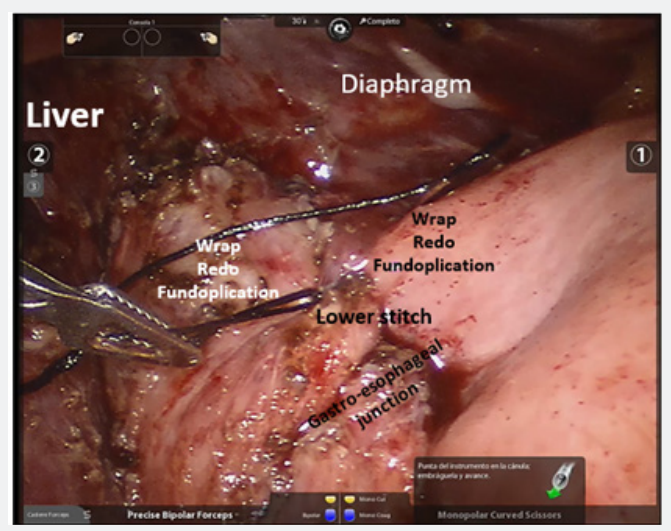

Figure 8: TO image, the redo funduplication was completed, the wrap was stabilized, the lower stitch and esophagogastric junction were observed. The RALRNF is finished.

The PO follow-up was at 8, 30, and 90 to 120 days, and then every 6 months. Between 90 and 120 days, upper GI tract X-Ray studies were carried out to evaluate the anatomic results of the surgery.

We used measures of central tendency. The data was entered into a spreadsheet in Microsoft Office Excel 2013 version.

In relation to ethical considerations of the study, being of an observational nature, it was not necessary to consent to enter the study to the patients. The Research Ethics Committee of the Hospital evaluated and approved the study. In Mexico, robot assisted surgery complies with the records and regulations of the Mexican health authorities. In our institution, robotic surgery is routinely authorized for execution. In order to perform the medical-surgical procedures, we obtained the informed consent in writing from the parents or guardians.

\section{Results}

In a 48-months period, we performed 19 RALRNF in pediatric patients. Of the procedures, $66.16 \%$ [12] were in male, and the rest were female; the average age was 10.3 years, ranging from 7 months to 17 years. The average height was $135.2 \mathrm{~cm}$, and ranged from 62 to $185 \mathrm{~cm}$, with an average weight of $36.3 \mathrm{~kg}$, ranging from 5.2 to $102 \mathrm{~kg}$; the smallest patient was 7 months old with a height of $62 \mathrm{~cm}$ and weight $5.2 \mathrm{~kg}$.

Our 3 most frequent GI procedures in the same period were, primary fundoplication [50], redo-fundoplication [19], and cholecystectomy [14] totaled 83 and represented $69.16 \%$ in this área, being the total 120 procedures GI, 13 of the RALRNF, they are part of the statistics of a previous publication [13].

Four patients $(21 \%)$ they have neurological impairment. The previous fundoplication, in 10 (52.6\%) it was open, laparoscopic in $6(31.6 \%)$ and robotics in $3(15.8 \%)$. One patient previously had 3 fundoplications, one open and two laparoscopic. In our casuistic the failure rate of the PRF with recurrence of symptoms was $6 \%$ (3 patients), and recurrence was presented at 3.5, 11 and 24 months.

The average console surgery time in 4 cases (21\%) of RF and gastrostomy procedures, including gastrostomy dismantlement, was $280 \mathrm{~min}$, varying the times from 235 to $328 \mathrm{~min}$, and in 15 cases $(79 \%)$ of RF only, the average time was $185 \mathrm{~min}$, varying the times from 115 to $360 \mathrm{~min}$.

The index transoperative complications was $21 \%$ (4 casos), gastric perforations in 2, a splenic lesion and an esophageal perforation. This lesion are considered incidental, they do not alter PO evolution of patients. 
The index conversion was $5.2 \%$ and PO complications $0 \%$. A failure of the RALRNF (5.2\%), occurred at 7 months of the PO, in our patient, there are 3 risk factors for fundoplication failure: PRF at 3 months of age, neurological impairment present and prompt recurrence with RRNF at 6.5 months of age and this second recurrence to the 13.5 months of age.

The transoperative surgical findings that caused the failure were, $\mathrm{HH}$ and partial or total wrap dehiscence of the fundoplication 10 cases $(52.63 \%)$ and only partial or total wrap dehiscence in 9 $(47.37 \%)$. In addition to the above, the common transoperative findings are multiple adhesions and the liver firmly attached to the stomach, which makes it difficult to identify anatomical structures, more bleeding and predisposes to cause injuries to various anatomical structures.

Only one patient (5.2\%) required hemotransfusion and conversion, his profile: a 9-year-old girl with a weight of $40 \mathrm{~kg}$, a fourth fundoplication, with $200 \mathrm{ml}$ of TO bleeding because the liver was firmly attached to the stomach, with multiple adhesions, difficult identification of its anatomy, a perforation occurred in the posterior face of the esophagus and the lack of adequate visibility of it, forced the conversion of the procedure to open.

The average PO hospital stay was 2.2 days, ranging from 1 to 5 days, and in 14 patients (73.7\%) was 1 to 2 days.

The average follow-up was 24.1 months, with ranging from 3 to 49 months.

\section{Discussion}

Successful LRNF in adults was first reported by Frantzides and Carlson [65], followed by reports of small series of cases, some in children. As van der Zee, et al, between December 1993 and December 1998, for 100 children who underwent a laparoscopic Thal procedure, 4 of them had to undergo a LRNF. A child was found with an intrathoracic wrap and a giant $\mathrm{HH}$, underwent a hernia repair and a redo-Thal, the procedure was more difficult due to a large $\mathrm{HH}$ and the technical limitations of the laparoscopic procedure. In two other children, the operation was relatively simple. The last child, the procedure had to be converted to open, and the authors concluded that, in children, it is feasible to LRNF after a previous laparoscopic fundoplication and does not increase morbidity [66].

Despite the increasing use of laparoscopic fundoplication, there has been relatively slow acceptance and significant criticism of its application for LRNF in children. The most major concern is that at redo surgery, adhesions are usually dense and tissue planes and gross anatomy can be distorted necessitating advanced laparoscopic skills.

Very high failure rates are reported until of $42 \%$ for RF [16]. Even though, Rothenberg insisted that in experienced hands, redo by laparoscopic is possible with good results: without conversions, under complication index, without mortality and with a low failure rate $6 \%$ of RF [4]. In other report of children, more serious complications have been reported in relation to LRNF such as esophageal perforation or gastric leak secondary to difficult dissection, scar tissue, and adhesions from prior surgery [67]. In another report, of LRNF, there was a $21.8 \%$ incidence of visceral injury in $307 \mathrm{RF}$. Authors comment on their experience that reoperative esophageal surgery can be one of the most challenging procedures that a surgeon will face. Anatomy can be severely distorted by scarring, fundoplication herniation, and unexpected findings. Experience and knowledge of normal and abnormal anatomy is critical to not only a safe operation but also effective resolution of the patient's problems [68].

The diversity of transoperative surgical findings that caused the failure are: $\mathrm{HH}$, wrap disruption, slipped wrap, crural stenosis, twisted wrap, and misplaced wrap, being the most frequents: $\mathrm{HH}$, slipped wrap and misplaced wrap [68]. Our findings in relation to these, coincide with that reported in other series, $\mathrm{HH}$ and/or partial or total slepped wrap.

In the LRNF, it is recommended: extreme caution during dissection, because is tedious and anatomic landmarks are distorted, and successful completion of RF requires familiarity with this abnormal anatomy. In particular, younger trainees should be carefully supervised by surgeons with sufficient experience in revision surgery, for the complex and laborious of these cases, longer learning curve, in order to prevent serious complications, reduce conversions and hemotransfusions.

Total thickness perforation of the gastric and esophageal wall is common during $\mathrm{RF}$ and should be detected and resolved. But also during the surgical dissection can cause partial thickness visceral injuries or weakening of its walls, which we must also detect and repair, since potentially they can evolve towards the perforation in PO period, and obviously it is synonymous with abdominal catastrophe and its consequences, not detect an esophageal-gastric perforation during the transoperative period.

After an exhaustive search using the terms: robot-assisted, laparoscopic, redo, fundoplication and children, it was not possible to locate publications as or similar to ours., and if there are a good number of publications on open and laparoscopic approach of the $\mathrm{RF}$, of which we have already made several considerations.

From our results the aspects that we consider transcendent are: the robotic procedures, fundoplication is surgical technique the most frecuente of robotic GI área [12], and the failure rate of the PRF (6\%) and the RRNF (5.2\%) are at the lower limits of what was reported in previous publications, without difference in relation to the antecedent of the primary fundoplication, with respect to those previously published, being in order of greater or lesser frequency in our casuistry, open, laparoscopic and robotic approach.

The transoperative findings found do not differ from those published in these cases of revision antireflux surgery, generally 
with dense and firm adhesions, anatomy altered and difficult to identify, risk of significant bleeding when the liver was firmly attached to the stomach. We caused gastric and esophageal perforations, and splenic lesion, only the esophageal perforation was of significance, since it forced to the only conversion to open surgery, the others did not alter the PO evolution, and no PO complications or mortality occurred, and the PO stay was brief in the majority of the patients.

Independently that we do not find similar publications in children, to have a reference in relation to our times of console surgery, we consider that they are satisfactory taking into account the complexity of the cases.

The patient who required hemotransfusion and conversion was his fourth fundoplication and found the liver firmly attached to the stomach, firm adhesions, it was difficult to identify its anatomy, it favored an incidental perforation of the esophagus, and it was not possible to visualize its exact site, which forced the conversion to open surgery.

The failures of the fundoplication are more related to patients of younger age, with ongoing retching in the PO period, extensive dissection of the hiatus in primary surgery, patients with neurological impairment and a shorter time to re-operation [30, 69]. Our patient who evolved with recurrence after the robotic fundoplication redo, meets 3 of the 5 factors mentioned above.

It is very important to perform a fundoplication with any of the 3 approaches, to reduce the risk of failure to take into account the following recommendations: minimal dissection of the hiatus, only enough mobilization of the esophagus for adequate creation of intraabdominal esophagus, creation of a tension-free and appropriate orientation, and positioning of the wrap and omission of esophagocrural sutures $[4,70,71]$. As well as, the use of biosynthetic mesh enhance hiatal repair, can reduce the risk of failure [72].

The need for a revision surgery after a fundoplication is a very variable event and, fundamentally, it is considered that it depends on the experience of the surgeon and the volume of surgeries depending on the center where he works, and the volume of cases (experience) per surgeon [14]. The results of published series of patients with redo, open or laparoscopic fundoplication show that the index of failure of this, is greater than in primary surgery $[29,31,62,69]$.

Robotic surgery has special applications in complex and reconstructive surgery. In the GI area in children, RRNF with HH or not and the correction of bilio-digestive anomalies, the robotic surgery is very profitable. In these procedures, from the open technique, we jump to robotic surgery. Due to the characteristics and advantages of this technology, it overcomes the limitations of conventional laparoscopy, we achieve a lower risk of conversions, fewer complications, less hemotransfusions, short stay PO, increase patient safety and the probability of failures and other reinterventions can be reduced, as our results show with medium- term follow-up.

Due to the limitations of conventional laparoscopic surgery, complex cases or reconstructive surgery in children can only be performed by a limited number of highly qualified surgeons, with advanced skills and sufficient experience [73].

Long-term follow-up outcomes from large prospective comparative (randomized) studies are necessary to prove these preliminary data in support of the use of robotic systems in pediatric patients with failed anti-reflux surgery.

\section{Conclusion}

The failed fundoplication is frequent, and RF is complex, difficult and laborious technique. In the redo, open or laparoscopic fundoplication, the failure rate is higher than in primary surgery and increases with other re-operations.

With the RALRNF, we achieved low risk of conversion, no complications, few hemotransfusions, short PO stay and low recurrence rate for our patients, for which we affirm that RALRNF is safe and effective and if offers advantages to the pediatric population.

There are few publications of RALRNF in children. Advantages of robotic surgery are application in complex surgeries, in small operating field, difficult access, delicate dissection, need control of hemostasis and intracorporeal sutures. Only expert pediatric surgeons solve them, by conventional laparoscopy.

Long-term follow-up outcomes from large prospective comparative (randomized) studies are necessary to prove these data's in support of the use of robotic systems in pediatric patients with failed anti-reflux surgery.

\section{Conflict of Interest}

The author declares to be Proctor of the da Vinci Surgical System and sometimes receives salary for advice to Surgeons in their first robotic procedures, from the marketing company in my country, as part of the support in the training of Surgeons by this company. But, in relation to the treatment of patients and the execution of this manuscript, no economic financing was received from commercial companies.

\section{References}

1. Razumosky AY, Alhasov AB, Bataev SH, Yekimovskaya EV (2015) Laparoscopic Fundoplication Nissen-Gold Standard Treatment of Gastroesophageal Reflux in Children. Eksp Klin Gastroenterol 1: 72-77.

2. Pearson EG, Downey EC, Barnhart DC, Scaife ER, Rollins MD, et al. (2010) Reflux esophageal stricture--a review of 30 years' experience in children. J Pediatr Surg 45(12): 2356-2360.

3. Rossi V, Mazzola C, Leonelli L, Gandullia P, Arrigo S, et al. (2016) Longterm outcome and need of re-operation in gastro-esophageal reflux surgery in children. Pediatr Surg Int 32(3): 277-283.

4. Rothenberg SS (2013) Two decades of experience with laparoscopic nissen fundoplication in infants and children: a critical evaluation of indications, technique, and results. J Laparoendosc Adv Surg Tech A 23(9): 791-794 
5. Gans AL (1994) Historical development of pediatric endoscopic surgery. In: Holcomb GW, (Ed). Pediatric Endoscopic Surgery. East Norwalk, CO: Appleton \& Lange:1-7.

6. Gans S, Berci G (1971) Advances in endoscopy of infants and children. J Pediatr Surg 6: 199-234.

7. Lobe TE, Schropp KP, Lunsford K (1993) Laparoscopic Nissen fundoplication in childhood. J Pediatr Surg 28(3): 358-360.

8. Moir CR (1993) Laparoscopy and thoracostomy in children. Curr Opin Pediatr 5(3): 333-40.

9. Schier F, Waldschmidt J (1994) Laparoscopic fundoplication in a child. Eur J Pediatr Surg 4(6): 338-340.

10. Meininger D, Byhahn C, Markus BH, Heller K, Westphal K (2001) Total endoscopic Nissen fundoplication with the robotic device "da Vinci" in children. Hemodynamics, gas exchange, and anesthetic management. Anaesthesist 50(4): 271-275.

11. Meininger DD, Byhahn C, Heller K, Gutt CN, Westphal K (2001) Totally endoscopic Nissen fundoplication with a robotic system in a child. Surg Endosc 15: 1360.

12. Cundy TP, Shetty K, Clark J, Chang TP, Sriskandarajah K, et al. (2013) The first decade of robotic surgery in children. J Pediatr Surg 48(4): 858-886.

13. Navarrete Arellano M, Garibay González F (2019) Robot-Assisted Laparoscopic and Thoracoscopic Surgery: Prospective Series of 186 Pediatric Surgeries. Front. Pediatr 7: 200.

14. Laje P, Blinman TA, Nance ML, Peranteau WH (2017) Laparoscopic fundoplication in neonates and young infants: Failure rate and need for redo at a high-volume center. J Pediatr Surg 52(2): 257-259.

15. Lopez-Fernandez S, Hernandez F, Hernandez-Martin S, Dominguez E, Ortiz R, et al. (2014) Failed Nissen fundoplication in children: causes and management. Eur J Pediatr Surg 24(1): 79-82.

16. Pacilli M, Eaton S, Maritsi D, Lopez PJ, Spitz L, et al. (2007) Factors predicting failure of redo Nissen fundoplication in children. Pediatr Surg Int 23: 499-503.

17. Ru W, Wu P, Feng S, Lai XH, Chen G (2016) Laparoscopic versus open Nissen fundoplication in children: A systematic review and metaanalysis. J Pediatr Surg 51(10): 1731-1736.

18. Thomas JF, Charlotte KK, Bjorn E, Ole S, Lars A, at al. (2015) Randomized Controlled Trial of Laparoscopic and Open Nissen Fundoplication in Children. Annals of Surgery 261(6): 1061-1067.

19. Meehan JJ, Meehan TD, Sandler A (2007) Robotic fundoplication in children: resident teaching and a single institutional review of our first 50 patients. J Pediatr Surg 42(12): 2022-2025.

20. Cundy TP, Rowland SP, Gattas NE, White AD, Najmaldin AS (2015) The learning curve of robot-assisted laparoscopic fundoplication in children: a prospective evaluation and CUSUM analysis. Int J Med Robot 11(2): 141-149.

21. Binet A, Fourcade L, Amar S, Alzahrani K, Cook AR, et al. (2019) Robot-Assisted Laparoscopic Fundoplications in Pediatric Surgery: Experience Review. Eur J Pediatr Surg 29(2): 173-178.

22. Friedmacher F, Till H (2015) Robotic-Assisted Procedures in Pediatric Surgery: A Critical Appraisal of the Current Best Evidence in Comparison to Conventional Minimally Invasive Surgery. J Laparoendosc Adv Surg Tech A 25(11): 936-943.

23. Mahida JB, Cooper JN, Herz D, Diefenbach KA, Deans KJ, et al. (2015) Utilization and costs associated with robotic surgery in children. J Surg Res 199(1): 169-176.

24. Cundy TP, Harling L, Marcus HJ, Athanasiou T, Darzi AW (2014) Meta analysis of robot-assisted versus conventional laparoscopic fundoplication in children. J Pediatr Surg 49(4): 646-652.
25. Garcia I, Salas de Armas IA, Pimpalwar A (2014) Current trends in pediatric robotic surgery. Bangladesh J Endosurg 2:15-28.

26. Westebring-van der Putten EP, Goossens RHM, Jakimowicz JJ, Dankelman J (2008) Haptics in minimally invasive surgery-a review. Minimally Invas Ther 17(1): 3-16.

27. Braumann C, Jacobi CA, Menenakos C, Ismail M, Rueckert JC, et al. (2008) Robotic-assisted laparoscopic and thoracoscopic surgery with the da Vinci system: a 4-year experience in a single institution. Surg Laparosc Endosc Percutan Tech 18(3): 260-266.

28. Vereczkel A, Bubb H, Feussner H (2003) Laparoscopic surgery and ergonomics: it's time to think of ourselves as well. Surg Endosc 17: 1680-1682.

29. Desai AA, Alemayehu H, Dalton BG, Gonzalez KW, Biggerstaff B, et al. (2016) Review of the Experience with Re-Operation After Laparoscopic Nissen Fundoplication. J Laparoendosc Adv Surg Tech A 26(2): 140143.

30. Aguilar R, Andrés A, Barrena S, Burgos L, Suárez O, et al. (2008) Reoperations in gastroesophageal reflux disease. Cir Pediatr 21(2):9295.

31. Koivusalo AI, Pakarinen MP (2018) Outcome of Surgery for Pediatric Gastroesophageal Reflux: Clinical and Endoscopic Follow-up after 300 Fundoplications in 279 Consecutive Patients. Scand J Surg 107(1): 6875.

32. Pascoe E, Falvey T, Jiwane A, Henry G, Krishnan U (2016) Outcomes of fundoplication for paediatric gastroesophageal reflux disease. Pediatr Surg Int 32(4): 353-361.

33. Miyano G, Yamoto M, Miyake H, Morita K, Kaneshiro M, et al. (2019) A Comparison of Laparoscopic Redo Fundoplications for Failed Toupet and Nissen Fundoplications in Children. J Indian Assoc Pediatr Surg 24(2): 100-103.

34. Rothenberg SS (2006) Laparoscopic redo Nissen fundoplication in infants and children. Surg Endosc 20(10): 1518-1520.

35. Celik A, Loux TJ, Harmon CM, Saito JM, Georgeson KE, et al. (2006) Revision Nissen fundoplication can be completed laparoscopically with a low rate of complications: a single-institution experience with 72 children. J Pediatr Surg 41(12): 2081-2085.

36. Chandra V, Dutta S, Albanese CT (2006) Surgical robotics and image guided therapy in pediatric surgery: emerging and converging minimal access technologies. Semin Pediatr Surg 15(4): 267-275.

37. Luebbe BN, Woo R, Wolf SA, Michael S Irish (2003) Robotically assisted minimally invasive surgery in a pediatric population: initial experience, technical considerations, and description of the da Vinci surgical system. Pediatric Endosurgery \& Innovative Techniques 7(4): 385-403.

38. Drasin T, Gracia C, Atkinson J (2003) Pediatric applications of robotic surgery. Pediatric Endosurgery \& Innovative Techniques 7: 377-384.

39. Meehan JJ (2009) Robotic surgery in small children: is there room for this? J Laparoendosc Adv Surg Tech A 19: 707-712.

40. Castle EP, Woods M, Srivastav SK, Thomas R, Davis R, et al. (2006) Transperitoneal versus extraperitoneal robotic-assisted radical prostatectomy: is one better than the other? Urology 68(5): 10771081.

41. Mikhail AA, Orvieto MA, Billatos ES, Zorn KC, Gong EM, et al. (2006) Robotic-assisted laparoscopic prostatectomy: first 100 patients with one year of follow-up. Urology 68(6): 1275-1279.

42. Khaira HS, Bruyere F, Malley PJ, Peters JS, Costello AJ (2006) Does obesity influence the operative course or complications of robotassisted laparoscopic prostatectomy. Brit J Urol Int 98(6): 1275-1278.

43. Tseng TY, Kuebler HR, Cancel QV, Sun L, Springhart WP, et al. (2006) Prospective health-related quality-of-life assessment in an initial 
cohort of patients undergoing robotic radical prostatectomy. Urology 68(5): 1061-1066.

44. Meehan JJ, Sandler A (2008) Robotic surgery: a single- institutional review of the first 100 consecutive cases. Surg Endosc 22:177-1782.

45. de Lamberg G, Fourcade L, Centi J, Fredon F, Braik K, et al. (2013) How to successfully implement a robotic pediatric surgery program: lessons learned after 96 procedures. Surg Endosc 27(6): 2137-2144.

46. Sinha SK, Haddad M (2008) Robot-assisted surgery in children: current status. J Robotic Surg 1(4): 243-246.

47. Alqahtani A, Albassam A, Zamakhshary M, Shoukri M, Altokhais T, et al. (2010) Robot-assisted pediatric surgery: how far can we go? World J Surg 34(5): 975-978.

48. Al-Bassam A (2010) Robotic-assisted surgery in children: advantages and limitations. J Robot Surg 4(1): 19-22.

49. Camps JI (2011) The use of robotics in pediatric surgery: my initial experience. Pediatr Surg Int 27(9): 991-996.

50. Marhuenda C, Giné C, Asensio M, Guillén G, Martínez Ibáñez V (2011) Robotic surgery: first pediatric series in Spain. Cir Pediatr 24(2): 9092.

51. Ballouhey Q, Villemagne T, Cros J, Szwarc C, Braik K, et al. (2015) A comparison of robotic surgery in children weighing above and below 15.0kg: size does not affect surgery success. Surg Endosc 29(9): 2643 2650 .

52. Bütter A, Merritt N, Dave S (2017) Establishing a pediatric robotic surgery program in Canada. J Robot Surg 11(2): 207-210.

53. Mattioli G, Pini Prato A, Razore B, Leonelli L, Pio L, et al. (2017) Da Vinci robotic surgery in a pediatric hospital. J Laparoendosc Adv Surg Tech A 27(5): 539-545.

54. Cundy TP (2015) Clinical Application and Evaluation of Robot-Assisted Surgery in Children (Thesis 2014).

55. Margaron FC, Oiticica C, Lanning DA (2010) Robotic-assisted laparoscopic Nissen fundoplication with gastrostomy preservation in neurologically impaired children. J Laparoendosc Adv Surg Tech A 20(5): 489-492.

56. Secin FP, Coelhjo R, Gardiner JM, Salcedo JGC, Puente R, et al. (2018) Robotic surgery in public hospitals of Latin-America: a castle of sand? World J Urol 36(4): 595-601.

57. Moldes JM, de Badiola FI, Vagni RL, Mercado P, Tuchbaum V, et al (2019) Pediatric Robotic Surgery in South America: Advantages and Difficulties in Program Implementation. Front Pediatr 7: 94.

58. Diez Del Val I, Martinez Blazquez C, Loureiro Gonzalez C, Vitores Lopez JM, Sierra Esteban V, et al. (2014) Robot-assisted gastroesophageal surgery: usefulness and limitations. J Robot Surg 8(2): 111-118.
59. Falkenback D, Lehane CW, Lord RV (2015) Robot-assisted oesophageal and gastric surgery for benign disease: antireflux operations and Heller's myotomy. ANZ J Surg 85(3):1 13-120.

60. Tolboom RC, Broeders IA, Draaisma WA (2015) Robot-assisted laparoscopic hiatal hernia and antireflux surgery. J Surg Oncol 112(3): 266-270.

61. Tolboom RC, Draaisma WA, Broeders IA (2016) Evaluation of conventional laparoscopic versus robot-assisted laparoscopic redo hiatal hernia and antireflux surgery: a cohort study. J Robot Surg 10(1): 33-39.

62. Rebecchi F, Allaix ME, Morino M (2017) Robotic technological aids in esophageal surgery. J Vis Surg 3: 7.

63. Dindo D, Demartines N, Clavien PA (2004) Classification of surgical complications: a new proposal with evaluation in a cohort of 6336 patients and results of a survey. Ann Surg 240: 205-213.

64. Clavien PA, Barkun J, de Oliveira ML, Vauthey JN, Dindo D, et al. (2009) The Clavien-Dindo classification of surgical complications: five-year experience. Ann Surg 250: 187-196.

65. Frantzides CT, Carlson MA (1997) Laparoscopic redo Nissen fundoplication. J Laparoendosc Adv Surg Tech A 7(4): 235-239.

66. van der Zee DC, Bax NM, Ure BM (2000) Laparoscopic refundoplication in children. Surg Endosc 14(12): 1103-1104.

67. Kane TD (2009) Laparoscopic Nissen fundoplication. Minerva Chir 64: 147-157.

68. Smith CD, McClusky DA, Rajad MA, Lederman AB, Hunter JG (2005) When fundoplication fails: Redo? Ann Surg 241: 861-869.

69. Baerg J, Thorpe D, Bultron G, Vannix R, Knott EM, et al. (2013) A multicenter study of the incidence and factors associated with redo Nissen fundoplication in children. J Pediatr Surg 48(6): 1306-1311.

70. St Peter SD, Barnhart DC, Ostlie DJ, Tsao K, Leys CM, et al. (2011) Minimal vs extensive esophageal mobilization during laparoscopic fundoplication: a prospective randomized trial. J Pediatr Surg 46(1): 163-168.

71. St Peter SD, Poola A, Adibe O, Juang D, Fraser JD, et al. (2017) Are esophagocrural sutures needed during laparoscopic fundoplication: A prospective randomized trial. J Pediatr Surg pii: S0022-3468(17): 30630-30639.

72. St Peter SD, Ostlie DJ, Holcomb GW (2007) The use of biosynthetic mesh to enhance hiatal repair at the time of redo Nissen fundoplication. J Pediatr Surg 42(7): 1298-1301.

73. DeNaeyerG, Schatteman P, Carpentier P, Mottrie A. (2013) Learning curve in robotic surgery: review of the literature (RALP, RAPN, and RARC). World J Urol 31: 455-61. 
(C) This work is licensed under Creative BY DOI: 10.19080/AJPN.2019.07.555781

\section{Your next submission with Juniper Publishers} will reach you the below assets

- Quality Editorial service

- Swift Peer Review

- Reprints availability

- E-prints Service

- Manuscript Podcast for convenient understanding

- Global attainment for your research

- Manuscript accessibility in different formats

( Pdf, E-pub, Full Text, Audio)

- Unceasing customer service

Track the below URL for one-step submission https://juniperpublishers.com/online-submission.php 